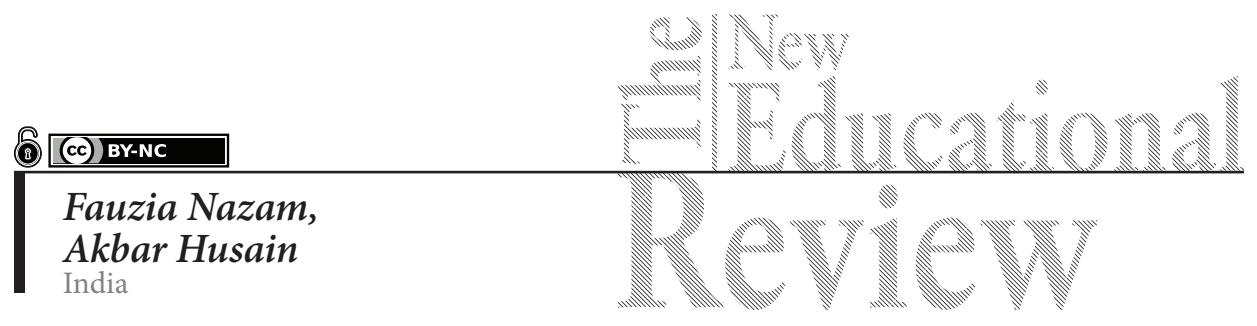

\title{
Further Validation of Spiritual Values Scale
}

DOI: 10.15804/tner.2020.61.3.16

\begin{abstract}
Many positive behaviours of youth are related to their values. In the field of education value assessment is central. However value expression is often very ambiguous. Therefore in an attempt to measure values with more universal, global, and cross cultural perspectives, Nazam, Husain and Khan (2015) developed a spiritual values scale. The initial validation of the scale was based on item content analysis, item reliability, internal consistency, and exploration of the factorial structure of spiritual values. But values are subjected to change due to many factors. Therefore revalidation of the scale remains an important research consideration. The present study extends the initial validation of the scale by using structure equation modelling to revalidate the dimensionality and reliability of the spiritual values scale. The sample consisted of 300 adolescents. The results suggested that out of 27 items 4 items to measure spiritual values are ineffective. The scale with 23 items still remains a reliable and valid psychological tool to assess the spiritual values of adolescents.
\end{abstract}

Key words: values, spiritual, construct, convergent, validity, reliability.

\section{Introduction}

Value cultivation and assessment have always been central to the character building and moral education of young people. Some values such as love, peace, respect, tolerance, forgiveness, co-existence, and non-violence are indispensable and should be accepted by all educators worldwide (Yojna, 2015). Values impact many behaviours of adolescents, such as career decision making (Nisha, Anjali, 
\&Sarita, 2016), pro-social decisions under social influence (Wei, Zhao, \& Zheng, 2016), academic honesty vs. dishonesty (Koscielniak \& Bojanowska, 2019), aggressive behaviour (Knofo, Danie, \& Kassabri, 2008), academic achievement (Tarabashkina \& Lietz, 2011; Asghar, Rathore, \& Siddiqui, 2019), participation in school activities (Hofer, Schmid, Fries, Zivkovic, \& Dietz, 2009), suicide attempts (Eskin, 2013) and sexual behaviour (Goodwin, Realo, Kwiatkowska, Kozlova, Nguyen, \& Nizharadze, 2002).

An attempt was made to assess the spiritual values of adolescents by Nazam, Husain, and Khan (2015). They developed a spiritual values scale with the conceptual definition that spiritual values are the integrative values of the human soul consisting of altruistic values, humanistic values, personal values, divine values, and affective values which lead to spiritual growth of the personality.

\section{The Spiritual Values Scale: An overview}

The original development and validation of the scale was a two stage process. To begin with, 60 values were listed based on the study of religious scriptures including the Holy Quran, the Bhagavad Gita, the Holy Bible, and the scriptures of Jainism and Buddhism. On the basis of 100\% agreement of experts in education, psychology, philosophy, and theology 40 spiritual values were selected for pilot study among adolescents studying in the schools of Aligarh city, India. The subjects had to respond on a five-point Likert rating scale, ranging from strongly agree to strongly disagree, showing the importance they attach to the values. Item analysis was done to check the reliability of each value. After item analysis 27 values were retained. In the second stage the scale was administered to 400 adolescents (200 males \& 200 females) studying in schools of Aligarh City, India. Twenty seven spiritual values were subjected to principle component analysis with orthogonal Varimax rotation to extract the factorial structure of the scale, which yielded five factors. These five factors were named as Altruistic values (Item no. 1Charity, 12-Kindness, 13-Love, 14-Modesty, 18-Reliance on God, 19-Repentance, 25-Truthfulness, and 26-Unity), Humanistic Values (Item no. 4-Courage, 5-Forgivenss, 9-Goodness, 16-Power, 22-Sincerity, and 27-Wisdom), Personal Values (Item no. 6-Fortitude, 7-Forbearance, 10-Humility, 17-Righteousness, 20-Selflessness, 21-Self-restraint, and 23-Steadfastness), Divine Values (Item no. 2-Compassion, 15-Piety), and Affective Values (Item no. 3-Contentment, 8-Gentleness of Speech and 24-Tenderness). The reliability (Internal Consistency) of the scale was measured by Cronbach's coefficient Alpha $(\alpha=0.911)$ for the full scale. For judging the internal consistency of this scale George and Mallery's (2003) rule of thumb was

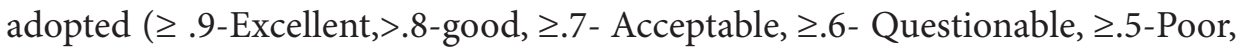


$\leq .5$-Unacceptable). Hence the scale has excellent reliability. The inter-factorial validity was also calculated to assure that all the factors are moderately correlated, confirming the dimensionality of this scale.

\section{Rationale for the study}

Researchers have marked corrosion of values by factors such as media, globalization, high stake exams, and family system change (Taneri, Gao, \& Johnson, 2016). Globalization has changed the nature of society from a classical- conservative society to an open society and this results in negative behaviour such as arrogance (Al Zyond, 2009). Social transformation changes the nature of society from collective civilization to an individualistic, self-development civilization that results in selfishness (Taneri, Gao, \&Jhonson, 2016). "Youth are being faced with peculiar problems in their societies that tend to challenge moral stance, they are surrounded with people who have thrown morality aside and are making it" (George \& Uyanga, 2014, p.43). Such changes may influence spiritual values such as selflessness, compassion, kindness, charity, unity etc. Therefore despite the good psychometric characteristics of spiritual values and growing interest in the use of this scale; revalidating the factorial structure of the scale remains equally important.

This study also aims to explore the convergent validity of the spiritual values scale. Convergent validity is related to construct validity (Gregory, 2007). It is a way of assessing the construct validity of a test (Campbell \& Fiske, 1959). Theoretically spiritual values and spiritual intelligence seem to be associated with each other. Spiritual intelligence has been conceptualized by different scholars as reflecting values and meaning (Sahebalzamani, Farahani, Abasi, \& Talebi, 2013). It is characterized by values such as compassion, forgiveness, modesty, and justice (Baheri, Akbarizade, \&Hatami, 2010). Compassion, harmony, forgiveness, modesty, and justice and wisdom are factorially derived values of the spiritual values scale (Nazam, Husain, \& Khan, 2015). Spiritual sources and values are also proposed as the content of spiritual intelligence which enhances the daily functioning of individuals (Sahebalzamnai, Farahani, Abasi, \& Talebi, 2013). Zoahar and Marshall (2003) used spiritual intelligence to develop "capacity for meaning, vision, and values" (p. 3). Wigglesworth (2012) define spiritual intelligence "as the capacity to behave with wisdom and compassion, while maintaining inner peace regardless of the situation" (p. 7). Spiritual intelligence helps in maintaining harmonious relationships (George, 2006). Therefore, finding the association between spiritual values and spiritual intelligence has a conceptual logic for confirming the convergent validity of the scale. 


\section{Objectives}

(1) To confirm the dimensionality of spiritual values scale.

(2) To find the convergent validity of the scale.

(3) To find the internal consistency (Cronbach's Alpha) of the scale.

\section{Methodology}

Research Design: Quantitative research method was used in this research.

Participants: This study consisted of 300 adolescents from the public schools of Aligarh city, India. The participants were randomly selected by using paper chits for simple random sampling. The age range of participants was from 12 to 19 years, with a mean age of $15.88(\mathrm{SD}=1.84)$. Those students who agreed to participate were given the consent form and asked to bring the consent signed by themselves and by their parents as well. Those participants, who brought the consent form back to the researcher, participated in the study.

Sample Size Determination: In this study power analysis was used to determine the sample size. The use of power analysis requires knowledge of three things, namely the alpha level adopted in the study, knowledge of the value of power the researcher aims at achieving in the test, and the effect size that is anticipated by the model (Uttley, 2019). In this study the alpha was adopted at the $\alpha=0.05$ level of significance. Further, the literature shows that while using Confirmatory Factor Analysis, a power of .80 is required for the $\alpha=0.05$ level associated with RMSEA (Kyriazos, 2018). The minimum sample size was measured by the $\mathrm{R}$ code of Preacher and Coffman (2006) that is based on Hancock and Freeman's (2001) interpolation method for computing power and the minimum sample size for RMSEA (Hancock \& Freeman, 2001; Hancock \& Muller, 2013; Preacher \& Coffman, 2006). The formula showed that the minimum sample size required is 200. In the present study the sample size is 300 , which was adequate for study. Another rule of thumb for sample size determination in a latent variable model with continuous outcome was suggested by Jackson (2003), that is the N:q ratio. According to this criterion, the sample-size $(\mathrm{N})$ to parameters ratio $(\mathrm{q})$ should be of 20:1 or at least 10:1. So the sample of current study is adequate in size. 


\section{Measures}

Spiritual Values Scale (SVS): The Spiritual Values Scale developed by Nazam, Husain, and Khan (2015) was used in this study. This scale has 27 spiritual values with a 5 point Likert rating scale ranging from strongly disagree to strongly agree. The scale represents five factors namely, (1) Altruistic Values (8 items) (2) Humanistic Values (7items) (3) Affective Values (3items) (4) Personal Values (7items) and (5) Divine values (2 items). The reliability of the original scale for a normative sample was .91 (Cronbach's Alpha, $\mathrm{N}=400$ ) (Nazam, Husain, Khan, 2015). For the current sample, the internal consistency of the scale was .908 (Cronbach's Alpha, $\mathrm{N}=300$ ). The scale showed excellent reliability for the current sample (George \& Mallery, 2003). The factorial validity of the scale was calculated by Exploratory factor analysis.

Spiritual Intelligence Self Report Inventory (SISRI): The SISRI developed by King (2008) was used to measure spiritual intelligence. The scale consisted of four factors namely, Critical Existential Thinking (CET) (items no. 1, 3, 5, 9, 13, 17, and 21), Personal Meaning Production (PMP) (item no. 7, 11, 15, 19, and 23), Transcendental Awareness (TA) (2, 6, 10, 14, 18, 20, and 22) and Conscious State Expansion (CSE) $(4,8,12,16$, and 24). There are twenty four items with a five point Likert rating scale ranging from $0-4$ where 0 stands for Not at all true of me, 1- Not very true of me, 2-Somewhat true of me, 3-Very true of me, and 4-Completely true of me. All the items are positively worded, only item number 6 has reverse coding. The participants were asked to rate each statement. The total score on spiritual intelligence was obtained by summing up all the scores on each item. The measure is found to be highly reliable as the internal consistency measured by Cronbach's alpha yielded the value of .920, the split-half reliability was .91 and the test- retest reliability over the period of four months was found to be .89 (King, 2008). Factorial validity was found to be good. For the present study the internal consistency reliability was .79 (Cronbach's Alpha), which is good (George \& Mallery, 2003)

Procedure: Before collecting data from the participants, Principals of Schools were approached and the purpose of research was shortly described to them. After seeking their permission the participants were briefed about the research purpose and then consent was taken from them and their parents in order to ensure their willingness to participate in the study. Then the SVS and SISRI along with a personal data sheet containing the demographic details were administered to them. Participants were asked to read the instructions carefully and answer the statements one by one in the required way. They were also told that if they had 
any query related to the understanding of items in the scales could feel free to ask for clarification. Once they completed the scale, they were thanked for their active participation in the research. Scoring of measures was done manually.

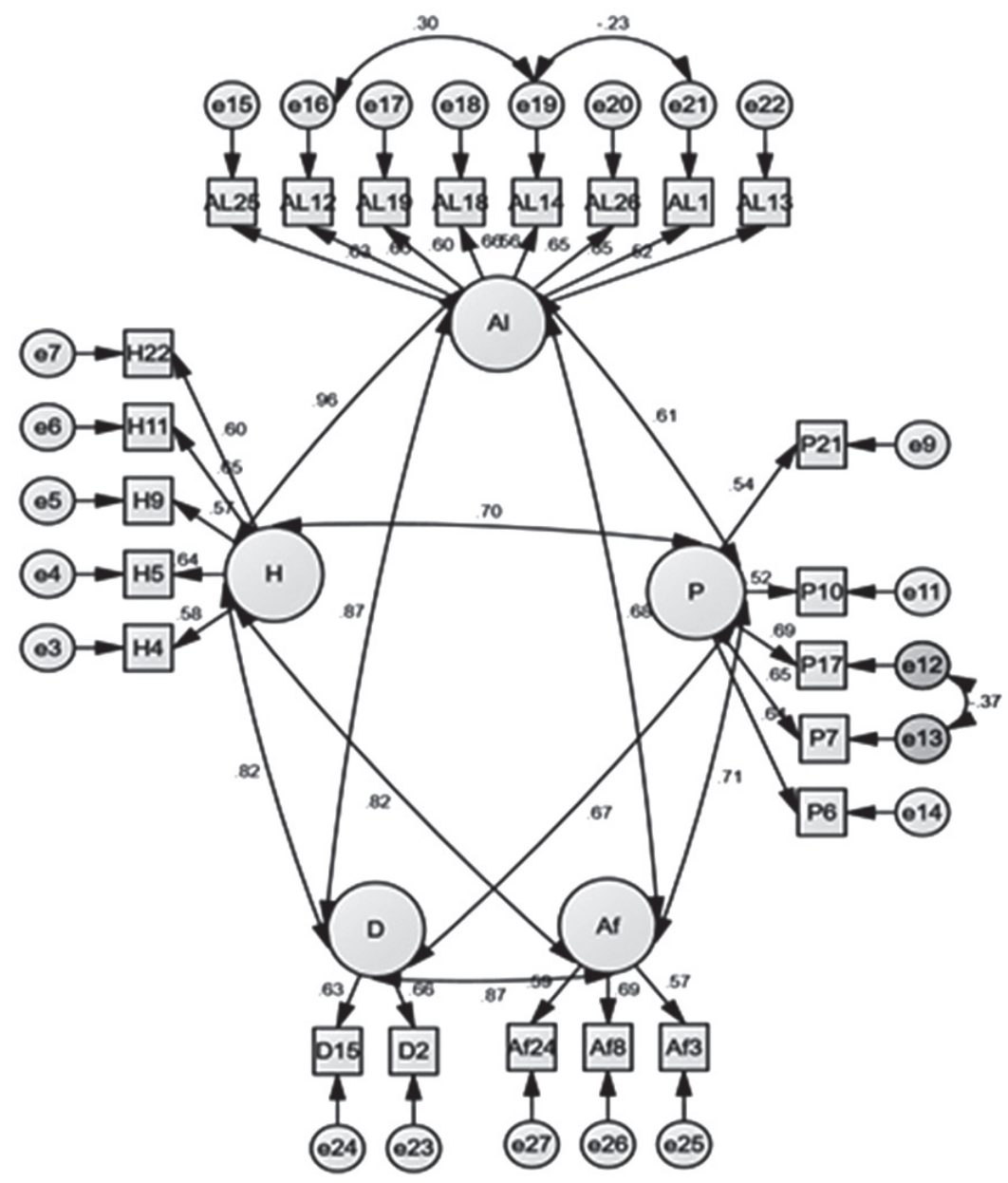

Figure 1. Measurement and Structural model of Spiritual Values Scale AlV = Altruistic Values, $H V=$ Humanistic Values, $P V=$ Personal Values, $A f V=A f f e c t i v e$ Values, $D V=$ Divine Values 


\section{Results}

Table 1. Showing Confirmatory Factor Analysis of Spiritual Values Scale and goodness of fit indexes

\begin{tabular}{lccccccc}
\hline Model of SVS & $\chi^{2}$ & Df & $\chi^{2 / D f}$ & CFI & AGFI & RMSEA & TLI \\
\hline Model 1 & 596.567 & 289 & 2.06 & .880 & .844 & .060 & .865 \\
\hline Model 2 & 394.709 & 217 & 1.45 & .921 & .875 & .052 & .908 \\
\hline
\end{tabular}

$\chi^{2}=$ Chi Square, $D f=$ Degree of Freedom, $C 2 / D f=C h i$ Square/Degree of Freedom, $C F I=$ Comparative Fit Index, AGFI= Adjusted Goodness of Fit Index, RMSEA= Root Mean Square Error of Approximation, $T L I=$ Tucker-Lewis index

Table 2. Showing the Correlation coefficients of Spiritual Values Scale and its factors with Spiritual Intelligence Self Report Inventory and its factors

\begin{tabular}{lcccc}
\hline \multirow{2}{*}{ Spiritual Values Scale } & \multicolumn{4}{c}{ Spiritual Intelligence Scale } \\
\cline { 2 - 5 } & CET & PMP & TA & CSE \\
\hline Altruistic Values & $.136^{\star}$ & $.284^{\star *}$ & $.380^{* *}$ & $.199^{\star *}$ \\
\hline Humanistic Values & $.138^{\star}$ & $.253^{* *}$ & $.353^{\star *}$ & $.159^{\star *}$ \\
\hline Personal Values & .003 & .029 & $.177^{\star *}$ & $.195^{\star *}$ \\
\hline Divine Values & $.126^{\star}$ & $.158^{\star *}$ & $.263^{* *}$ & $.158^{\star *}$ \\
\hline Affective Values & .094 & $.177^{\star *}$ & $.248^{\star *}$ & $.469^{\star *}$ \\
\hline Total & \multicolumn{5}{c}{$.295^{\star *}$} \\
\hline
\end{tabular}

CET-Critical Existential Thinking, PMP-Personal Meaning Production, TA-Transcendental Awareness, CSE-Conscious State Expansion

Level of significance: $p<0.05$ (one tailed)

Table 3. Showing Average Variance Extracted (AVE), Composite reliability of the factors and Internal Consistency of Spiritual Values Scale

\begin{tabular}{lcc}
\hline \multicolumn{1}{c}{ Factors } & AVE & $\begin{array}{c}\text { Composite Relia- } \\
\text { bility }\end{array}$ \\
\hline Humanistic Values (Item no. 4,5,9,11,22) & .37 & .78 \\
\hline Altruistic Values $(1,12,13,14,18,25,26)$ & .38 & .95 \\
\hline Personal Values $(6,7,10,17,21)$ & .374 & .74 \\
\hline Divine Values $(2,15)$ & .416 & .50 \\
\hline Affective Value $(3,8,24)$ & .383 & .64 \\
\hline Spiritual Values Scale $($ Total Items=23) & Cronbach's Coefficient Alpha $(\alpha)=.908$ \\
\hline
\end{tabular}




\section{Discussion}

A structural equation model approach was used to examine the factorial structure of the spiritual values scale. Confirmatory Factor Analysis (CFA) is the measurement technique in the structural equation model which was used to confirm the factorial structure. The standardised factor loading of items was analysed by the standardised factor weight $1=0.50$ with the concept that each item will explain $25 \%$ variance in the factor. For the first model (Table 1) all the items showed adequate factor loading except item numbers 16, 27, 20, and 23 (Power, Wisdom, Selflessness, and Steadfastness). Also the Modification indices (MI) after application of the Lagrange multiplier test showed covariance between items 7 and 17; 16 and 19;19 and 21. Resultantly the second model emerged (Table 1). In Model 2 all the items showed adequate standardised factor loading $(1>0.50)$ and individual reliability $\left(\mathrm{r}^{2}=.25\right)$.

In CFA $\chi^{2}$ measures the goodness of fit of the model to the data. The goal is to reject the null hypothesis. For Model 2 (Table 1 ) the $\chi^{2}=394.709, \mathrm{p}<.00$. So apparently it seems that the model does not fit the data. "However, in the case of a large sample, it is normally impossible to fail to reject the null hypothesis" (Kacmar \& Carison, 1997, p.653).Further $\chi^{2}$ is likely to be inflated in a large sample size (Brown, 2006). Therefore while using a large sample the value of $\chi^{2}$ is divided by degrees of freedom and if the $\mathrm{X}^{2} / \mathrm{df}$ ratio is less than 5 the model indicate fit to the data (Wheaton, Muthen, Alwin, \& Summer, 1977). For the present study $\chi^{2} / \mathrm{df}=1.45$ that shows the model fits to the data. In combination of $\mathrm{X}^{2}$ other indices are used.GFI is another indices for good-of-fit of the model. Model 2 showed a GFI $=.902$. However for model parsimony the value of AGFI-Adjusted Goodness of Fit Index shall be considered in CFA. The value of the AGFI should exceed .80 (Hooper, et al., 2008; Hu \& Bentler, 1999; Kline, 2005). The value for the current model is within the accepted range (AGFI= .875 Model 2). The value of CFI-Comparative fit index shows that proportion of variance and it overcomes the difficulties associated with sample size (Modeskar, Williams, \& Holohan, 1994). The value of CFI should be equal or greater than .90 (Hooper, et al., 2008; Kline. 2005; Mulaik, James, Van, Alstine, Bennet, Lind, \& Stillwell, 1989; Rigdon, 1996).

Model 2 shows goodness of fit $(\mathrm{CFI}=.921)$. Further, the suggested value of RMSEA (Root mean square error of approximation) of $<0.05$ (Good), 0.05-0.08 (Acceptable), and 0.08-0.1 (Marginal), >0.01(Good) (Fabrigar, McCallum, Wegener, \& Strahan, 1999), upper limit of 0.07 (Steiger, 2007). For the current model RMSEA is within the acceptable range (RMSEA $=.052$ ). The value of TLI should be greater than .90 (Hooper et al., 2008; Hu \&Bentler, 1999; Zainudin, 2012). For 
this model it is .908 (Table 1). Hence all the indices of CFA confirm the goodness of fit of the model.

The convergent validity of SVS was determined by two methods. One by correlating the scores of the spiritual values scale with the spiritual intelligence self-report inventory (King, 2008). Another method used was Average Variance Extracted (AVE) in which each factor of the spiritual values scale was taken into consideration. The spiritual values scale has significant positive correlation with the spiritual intelligence self-report inventory $(\mathrm{r}=.295, \mathrm{p}<0.01)($ Table 2$)$. All five factors of the spiritual values have positive significant correlation with most of the factors of spiritual intelligence. Although the correlation is weak, but we cannot expect two different constructs to be perfectly correlated for convergent validity.

Secondly, though the AVE is less than .50 (Table3), if composite reliability is higher than .60 , the convergent validity of the scale is still adequate (Fornell \& Larker, 1981). For good convergent validity CR should be $\geq 0.707$ (Gefen, Straub, $\&$ Boudrean, 2000). Hence the convergent validity of the spiritual values scale is adequate and good. Also the scale has excellent internal consistency reliability (Cronbach's Coefficient Alpha= 0.908, N=23) (George \& Mallery, 2003).

Thus the spiritual values scale still stands as a valid and reliable psychological measure for the assessment of values in adolescents. But it is worth noting that the values of selflessness, power, wisdom and steadfastness were not confirmed by the model. Further, the results of this study should be seen as having certain limitations. Although the correlation of spiritual values and spiritual intelligence is positive and significant which fits the theoretical perspective the correlation is weak, ranging from .177 to.469. Therefore, the authors suggest that future researchers should first reconfirm the factorial structure of the Spiritual Intelligence Self Report Inventory in the Indian context and then proceed with correlation analysis. Future research may increase the reliability of the test criterion by following this procedure. Also, the SVS is validated in the Indian culture. However, the practice and preaching of values is subject to cultural change. Therefore, cross cultural validation of this scale is also needed.

\section{Application}

This scale can be used for the assessment of values of students. The scores can be used to understand the value system adopted by students and they can then be accordingly assisted by educators. The purpose of education is not only acquisition of knowledge, but also the cultivation of values. Therefore, curriculum design requires both values assessment and value education. The role of teachers in values clarification is very important to help 
students make wise choice (Laxmmi, 2009). Spiritual values should be cultivated for the spiritual development of adolescents.

\section{Ethical Consideration}

Informed consent was collected from the participants. Further, the study was approved by the Department of Psychology, Aligarh Muslim University, Aligarh. (India).This study was also conducted in accordance to Helsinki (1975) guidelines which were revised in 2000.

\section{Funding}

This study did not receive any funding.

\section{Conflict of interest}

The author declares no conflict of interest.

\section{Acknowledgment}

The authors are thankful to the Principals of Schools for cooperating with the researchers.

\section{References}

Al-Zyoud, M.S.N. (2009). The impact of globalization on Jordan society. Dirasat, Educational Sciences, 36(1), 174-184.

Asghar, M.A., Rathore, F., \&Siddiqui, D. (2019). The impact of religious practices and valueson academic achievement of students at senior secondary level. Journal of Education \& Practice, 10(2), 38-43.

Bagheri, F., Akbarizade, F., \&Hatami, H. (2010). The relationship between nurses' spiritual intelligence and happiness in Iran. Procedia Social Behaviour Sciences, 5, 1556-1561.

Brown, T.A. (2006). Confirmatory factor analysis for applied research. New York: The Guilford Press.

Campbell, D.T., \& Fiske, W.D. (1959).Convergent and divergent validity by multitrait-multi method matrix.Psychological Bulletin, 56, 81-105.

Cieciuch, J. (2011). Integration of Schwartz's value theory and Scheler's concept of values in research on the development of structures of values during adolescence. Polish Psychological Bulletin, 42(4), 205-219.

Eskin, M. (2013). The effects of individualistic-collectivistic value orientations on nonfatal suicidal behavior and attitudes in Turkish adolescents and young adults. Scandinavian Journal of Psychology, 54(6), 493-501.

Fabrigar, L.R., MacCallum, R.C., Wegener, D.T., \&Strahan, E.J. (1999). Evaluating the use of exploratory factor analysis in psychological research, Psychological Methods, 4(3), 272-299.

Gefen, D., Straub, D., \&Boudrean, M.C. (2000). Structure equation modelling and regres- 
sion: Guidelines for research practice. Communication of the Association for Information System, 4(1), 1-44.

George, D., \& Mallery, P. (2003). Reliability analysis. SPSS for Windows, step by step: a simple guide and reference (14 ${ }^{\text {th }}$ ed.) Boston: Allyn \& Bacon, 222-232.

George, I.N., \&Uyanga, D. (2014). Youth and moral values in changing society. Journal of Humanities \& Social Sciences, 19(6), 40-44.

George, M. (2006).Practical application of spiritual intelligence in the workplace. Emerald Group Publishing Limited, 3-5.

Goodwin, R., Realo, A., Kwiatkowska, A., Kozlova, A., Nguyen, L.L.A., \& Nizharadze, G. (2002).Values and sexual behavior in central and Eastern Europe. Journal of Health Psychology, 7, 45-56.

Gregory, R.J. (2007). Psychology testing: History, principle, and applications (5 ${ }^{\text {th }}$ ed.), Boston: Ally \& Bacon.

Hancock G.R., \& Muller, R.O. (2013). Structure equation modelling (2 ed.). Charolotte, NC: Information Age Publishing.

Hancock, G. R, \& Freeman, M.J. (2001) Power and sample size for the RMSEA test of not close fit in structural equation modeling. Educational \& Psychological Measurement, 61, 741-758.

Hofer, M., Schmid, S., Fries, S., Zivkovic, I., \& Dietz, F. (2009). Value orientations and studying in school-leisure conflict: A study with samples from five countries. Learning and Individual Differences, 19(1), 101-112.

Hooper, D., Coughlan, J., \& Mullen, M. (2008). Structural Equation Modelling: Guidelines for determining model fit. Dublin Institute of Technology Articles, 6(1), 53-60.

Hu, L.T., \& Bentler, P.M. (1999).Cutoff criteria for fit indexes in covariance structure analysis: Conventional criteria versus new alternatives. Structural Equation Modeling: A Multidisciplinary Journal, 6(1), 1-55.

Husain, A., Zehra, S., \& Jahan, M. (2015). Standardization of employees spiritual values scale (ESVS). Indian Journal of Positive Psychology, 6(3), 321-322.

Kacmar, K.M.,\&Carsion, D.S. (1997). Further validation of the perception of politics scale (POPS): A multiple sample investigation. Journal of Management, 23(5), 627-658.

King, D.B. (2008). Rethinking claims of spiritual intelligence: A definition, model, and measure. Unpublished master thesis. Ontario, Canada: Trent University.

Kline, R.B. (2005). Principles and practice of structural equation modeling ( $2^{\text {nd }}$ ed.). NewYork:Guilford Press.

Knafo, A., Daniel, E., \&KhouryKassabri, M. (2008).Values as protective factors against violent behavior in Jewish and Arab high schools in Israel.Child Development, 79(3), 652-667.

Koscielniak, M., \&Bojanowska, A. (2019). The role personal values and student achievement in academic dishonesty. Frontiers in Psychology, 10, 1-7.

Kyriazos, J. (2018). Applied psychometrics: Sample size and sample power considerations in factor analysis (EFA,CFA) and SEM in general. Psychology, 9, 2207-2230. 
Larcker, D.F. (1981).Evaluating structure equation model with unobservable variable and measurement error. Journal of Marketing Research, 18(1), 39-50.

Laxmi, C. (2009). Value education: An Indian perspective on the need of moral education in a time of rapid social change. Journal of College \& Character, 10(3), 1-7.

Medsker, G.J., Williams, L.J.,\& Holohan, P.J. (1994).A review of current practices for evaluating causal models in organizational behavior and human resources management research. Journal of Management, 20, 439-464.

Nazam, F., Husain, A., Khan, S.M. (2015).Manual of Spiritual Values Scale. India, Agra :National Psychological Corporation.

Nisha, C., Anjali, M., \& Sarita, S. (2016).A study on the impact of values on career decision making of adolescents. International Journal of Research in Applied Science \& Engineering Technology, 4(10), 395-398.

Preacher, K.J., \& Coffman, D.L. (2006). Computing power and minimum sample size for RMSEA [Computer software]. Available from http://quantpsy.org/

Rigdon, E.E. (1996). CFI versus RMSEA: A comparison of two fit indexes for structural equation modeling. Structural Equation Modeling: A Multidisciplinary Journal, 3(4), 369-379.

Sahebalzamnai, M., Farahani, H., Abasi, R., \&Talebi, M. (2013). The relationship between spiritual intelligence with psychological well-being. Iranian Journal of Nursing \& Midwifery Research, 18(1), 38-41.

Steiger, J.H. (2007). Understanding the limitations of global fit assessment in structural equation modelling. Personality and Individual Differences, 42(5), 893-98.

Taneri, P.O., Gao, S.J., \& Johnson, S.R. (2016). Reasons for the deterioration of moral values: Cross cultural comparative analysis. International Academic Conference Proceedings. Boston, USA.

Tarabashkina, L., \&Lietz, P. (2011). The impact of values and learning approaches and academic discipline influences. Issues in Educational Research, 21(2), 210-216.

Uttley, J. (2019). Power analysis, sample size, and assessment of statistical assumptionsImproving the evidential value of lighting research. LEUKOS, 15(2), 143-162.

Wei, Z., Zhao, Z., \& Zheng, Y. (2016). Moderating effect of social value orientation on the effect of social influence in prosocial decisions. Frontiers in Psychology, 7, 1-9.

Wheaton, B.B., Muthen, B., Alwin. D.F.,\& Summers, G.F. (1977). Assessing reliability and stability in panel models.In D.R. Heise (Ed.).Sociological Methodology. San Francisco: Jossey-Bass.

Wigglesworth, C. (2012). SQ21: The 21 skills of spiritual intelligence. New York: Selected Books.

ZainudinHjAwang. (2012). Structural Equation Modelling Using AMOS Graphic. Kuala Lumpur: UiTM Press.

Zohar, D., \& Marshall, I. (2000).SQ_Spiritual intelligence, the ultimate intelligence. London: UL copy. 